\title{
TRABALHO E SAÚDE NO MOVIMENTO SINDICAL: A EXPERIÊNCIA DA SECRETARIA DE SAÚDE DO TRABALHADOR DO SINDISPREV-RS
}

\author{
Work and health in the trade union movement: the experience of the Occupational Health \\ Secretariat of SINDISPREV-RS
}

Travail et santé dans le mouvement syndical: l'expérience du Secrétariat de Santé du Travailleur du SINDISPREV-RS

Trabajo y salud en el movimiento sindical: la experiencia de la Secretaría de Salud Ocupacional del SINDISPREV-RS

Fabiane Konowaluk Santos Machado1 http://orcid.org/0000-0001-9455-3009.

Psicóloga - CRP 07/08713. Secretaria de Saúde do Trabalhador/SINDISPREVRS. Mestre e Doutora em Serviço Social/PUCRS. Doutoranda em Psicologia Social e Institucional/UFRGS. Conselho Federal de Psicologia, Porto Alegre, Rio Grande do Sul, Brasil.

Maria Dulcinéia Martins Batista ${ }^{2}$ https://orcid.org/0000-0001-5202-2840. Assistente Social - CRESS 12181 - 10 região. Secretaria de Saúde do Trabalhador - SINDISPREV/RS Universidade Federal do Rio Grande do Sul, Porto Alegre, Rio Grande do Sul, Brail.

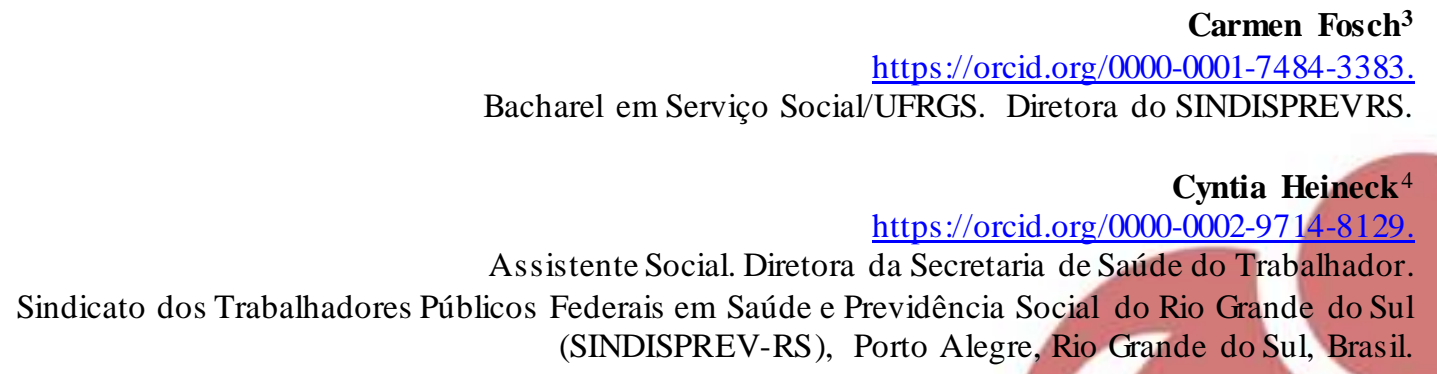

\section{Resumo}

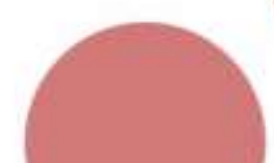

Este artigo resulta da experiência do trabalho interdisciplinar da Secretaria de Saúde do Trabalhador que compõe o Sindicato dos Trabalhadores Federais da Saúde, Trabalho e Previdência no Rio Grande do Sul (SINDISPREV RS). Objetiva apresentar a metodologia de trabalho desenvolvida e seus diferentes enfoques a partir da equipe técnica integrada por Assistente Social e Psicóloga do Trabalho, com foco na saúde do trabalhador. As ações emergem a partir de demandas de trabalhadores públicos, que buscam o sindicato com questões relacionadas à

\footnotetext{
${ }^{1}$ fabiane.konowaluk@gmail.com

2 dulcybatysta@gmail.com

3 kfosch@hotmail.com

${ }^{4}$ cyntiaheineck@yahoo.com.br
} 
saúde e ao trabalho. A realidade trazida pelos trabalhadores que buscam auxílio e orientação apresenta agravamentos em relação a condições de saúde, indicando a falta de trans parência e de ações destinadas à proteção da saúde no serviço público federal. O relato de experiência demonstra o importante papel e a responsabilidade do sindicato e apresenta, como resultado, a contribuição para o fortalecimento do movimento sindical e de sua categoria, operadora das políticas públicas no Brasil. Busca-se, com isso, a visibilidade dos graves problemas apresentados e maior atenção às ações de promoção e proteção da saúde de seus operadores por parte dos gestores na luta contra o desmonte dos órgãos públicos e consequentemente, de seus serviços.

Palavras-chave: Saúde do Trabalhador; Sindicatos; PsicologiaOrganizacional; Serviço Social.

\begin{abstract}
This article is a result of the interdisciplinary work experience of the Occupational Health Secretariat, developed along with the Health, Labor and Social Security Workers' Union of the state of Rio Grande do Sul (SINDISPREVRS).It aims to present the working methodology developed as well as its different approaches used by the technical team composed ofsocial worker and psychologist, focusing on occupational health. The actions emerged from the demands of public workers, who seek the service with is sues related to health and work. The reality brought to the union presents health conditions worsening, thus indicating the lack of transparency and actions aimed at protecting these workers' health.The case report demonstrates the important role and responsibility of the union and shows, as a result, the contribution to the strengthening of the union movement and its category, which operates public policies in Brazil. Therefore, it is expectedto give visibility tothe serious problems presented and greater attention to actions taken by managers to promote and protect the health of those who operate public policies, in the fight against the dismantling of public policies.
\end{abstract}

Keywords: Occupational Health; Labor Unions; Organizational Psychology; Social Work.

\title{
Résumé
}

Cet article résulte de l'expérience du travail interdisciplinaire du Secrétariat de Santé du Travailleur, développé ensemble au Syndicat des Travailleurs Fédéraux de Santé, Travail et Sécurité Sociale du Rio Grande do Sul (SINDISPREV-RS). Son but est présenter la méthodologie du travail développée et ses différents approches à partir de l'équipe technique intégrée par le Travailleur Social et Psychologue, centrée sur la santé du travailleur. Les actions émergent à partir de demandes des fonctionnaires, qui cherchent le service avec les questions rapportées à la santé et au travail. La realité apportée au syndicat présente des aggravations par rapport aux conditions de santé, en indiquant la manque de transparence et des actions destinées à la protection de la santé de ces travailleurs. Le récit montre l'important rôle et la responsabilité du syndicat et présente, comme résultat, la contribution pour le renforcement du mouvement syndical et de sa catégorie, opératrice des politiques publiques au Brésil. On cherche, avec cela, la visibilité des graves problèmes présentés et une plus grande attention aux actions de promotion et protection de la santé des opérateurs des politiques publiques de la part des gérants dans la lutte contre le démantèlement des politiques publiques.

Mots-clés: Santé du Travailleur; Syndicats; Psychologie Organisationnelle; Service Social.

\section{Resumen}

Este artículo proviene de la experiencia de trabajo interdisciplinario de la Secretaría de Salud Ocupacional, desarrollado al Sindicato de los Trabajadores Federales de Salud, Trabajo y Seguridad en Rio Grande do Sul (SINDISPREV-RS). Tiene el objetivo de presentar la metodología de trabajo desarrollada y sus diferentes enfoques a partir del equipo técnico integrado por asistente socialy psicóloga, con foco en la salud del trabajador. Las acciones emergen a partir de demandas de trabajadores públicos, que buscan el servicio con preguntas relacionadas con salud y trabajo. La realidad traída al sindicato presenta deficiencia en relación a las condiciones de salud, indicando la falta de transparencia y de acciones destinadas a la protección de la salud de esos trabajadores. El relato de experiencia demuestra el importante papel y la responsabilidad del sindicato y presenta, como resultado, la contribución al fortalecimiento del movimiento sindical y de su categoría, operadora de las políticas públicas en Brasil. Se busca, con eso, la visibilidad de los graves problemas presentados y mayor atención a las acciones de promoción y protección de la salud de los operadores de las políticas públicas por parte de los gestores en la lucha contra el desmonte de las políticas públicas.

Palabras clave: Salud Laboral; Sindicatos; Psicología de las Organizaciones; Servicio Social. 


\section{INTRODUÇÃO}

O presente artigo trata da experiência do trabalho desenvolvido junto à Secretaria de Saúde do Trabalhador (SST) integrante do Sindicato dos Trabalhadores Federais da Saúde, Trabalho e Previdência no Rio Grande do Sul (SINDISPREV-RS) em Porto Alegre. O tema é relevante porque implica no aporte que o trabalho realizado, em formato interdisciplinar na interface permanente que a Psicologia Social do Trabalho e o Serviço Social, propõe à entidade, utilizando-se de seus referenciais teórico-metodológicos, que são próprios de cada profissão, mas integrados ao campo da saúde do trabalhador.

Conforme o estatuto do Sindicato dos Trabalhadores Federais em Saúde, Trabalho e Previdência no Estado do Rio Grande do Sul (SINDISPREV-RS, 2013), a entidade sindical teve sua fundação em 11 de outubro de 1988 e representa os trabalhadores/trabalhadoras públicos vinculados sob qualquer forma ao Ministério da Saúde, ao Instituto Nacional do Seguro Social (INSS), ao Ministério do Trabalho e Emprego (MTE), à Agência Nacional de Vigilância Sanitária (ANVISA) e à Fundação Nacional de Saúde (FUNASA), com base no estado do Rio Grande do Sul. Cabe ressaltar que o sindicato surge a partir das lutas dos trabalhadores públicos federais dos extintos Instituto de Administração Financeira da Previdência Social (IAPAS), Instituto Nacional de Assistência Médica da Previdência Social (INAMPS) e Instituto Nacional de Previdência Social (INPS), sendo que a partir do fim da década de 1970 os trabalhadores se organizaram para fundar um sindicato comum à categoria.

O SINDISPREV-RS é uma entidade que conta com oito mil, quatrocentos e sessenta e seis filiados e representa todos os trabalhadores federais, ativos e aposentados, das categorias já mencionadas. Atualmente é formado por uma diretoria colegiada com 48 membros, e sua configuração organizacional é composta pelas seguintes Secretarias: Coordenação e Organização (SORG); Administração e Finanças (SAF); Assuntos Jurídicos; Imprensa; Gênero e Combate à Discriminação Racial; Aposentados; Políticas Sociais; Trabalhadores da Secretaria Regional do Trabalho (SRTE); Formação; Trabalhadores do Sistema Único de Saúde (SUS); Trabalhadores do Instituto Nacional do Seguro Social (INSS); Trabalhadores da Agência Nacional de Vigilância Sanitária (ANVISA); Saúde do Trabalhador (SST); Eventos; Comissão de Ética e Conselho Fiscal.

As reformas na administração federal propostas pelo governo de Michel Temer (20162018) acabaram impactando direta e profundamente a vida laboral dos trabalhadores federais atendidos pelo sindicato, o que resulta em diversos danos e demandas referentes à saúde desses trabalhadores. As mudanças na gestão dos órgãos partícipes foram profundas, como, por 
exemplo, o desmonte da previdência social brasileira e as profundas mudanças no âmbito do trabalho e emprego no país, referentes à mudanças no próprio Ministério do Trabalho e à reforma da Consolidação das Leis do Trabalho (Lei n. 13.467/2017, que alterou a CLT), o que inclui a terceirização irrestrita também nos serviços públicos, apresentando um grande retrocesso e descaso com o trabalhador público, operador das políticas públicas e sociais no país. Este desmonte dos serviços públicos é observado por Skinner (2017) e Biavaschi (2017) ao tratar as questões referentes ao projeto neoliberal e suas reformas reestruturantes, propostas e implantadas no triênio 2016-2018 no Brasil.

O impacto destas reformas no âmbito do trabalho e do emprego podem ser observados, na fragilidade, ou até mesmo ausência de vínculo trabalhista, o que está diretamente relacionado às perdas de direitos trabalhistas e de benefícios indiretos já conquistados e consequentemente, às perdas salariais. Estas reformas acabam por reforçar o trabalho precarizado (Alves, 2007) e consequentemente, a precarização da saúde dos trabalhadores, caracterizada pela fragilização física, mental e subjetiva dos trabalhadores (Santos, F. Giongo, C. Mendes, J., 2016). A fragilização do reconhecimento social, é um aspecto fundamental para a saúde mental e que deixa de compor o universo do trabalho, atuando diretamente na alienação dos trabalhadores e causando a ausência do coletivo de trabalho, responsável pela intensa fragilização dos profissionais, que acabam respondendo sozinhos pelo seu próprio sofrimento e adoecimento (Franco e cols., 2010:231).

Além disso, a modernização com o uso de novas tecnologias para acesso aos serviços públicos provoca mudanças na organização de vida e trabalho do trabalhador que está inserido nesse processo. A exigência da produtividade muitas vezes torna-se dispositivo de opressão nos locais, provocando diversas situações que ocasionam conflitos característicos das relações de trabalho, culminando no adoecimento. O modo avassalador com que essas transformações do mundo do trabalho chegam a esses trabalhadores é preocupante para as mais diversas áreas do conhecimento (Antunes e Alves, 2004), mas principalmente para as entidades sindicais, que também possuem uma análise aprofundada da realidade por ora apresentada. O recuo dos direitos sociais tem sido o maior impacto que ataca e desmancha uma história de lutas por condições mais dignas de vida e trabalho, conforme Alves, (2017). O autor ainda chama atenção para as estratégias utilizadas neste período, como a redução do custo da força de trabalho, operacionalizada através das reformas legais acerca do trabalho terceirizado e da própria reforma trabalhista, a limitação dos gastos orçamentários públicos, que impacta diretamente na redução dos programas sociais e políticas públicas, ocasionando diretamente o sucateamento da Previdência Pública, brecha para a próxima reforma no país. 
É nesse contexto que o SINDISPREV-RS, através do trabalho da sua Secretaria de Saúde do Trabalhador (SST) está inserido. Assim, o sindicato evidencia as necessidades de discutir junto aos trabalhadores públicos federais o tema da saúde do trabalhador e da trabalhadora e de pensar estratégias de enfrentamento junto à categoria que representa. Em março de 2014 foi definido pela direção do SINDISPREV-RS a reativação da Secretaria da Saúde do Trabalhador, a fim de intervir nas questões referentes ao adoecimento da categoria frente aos novos modelos de gestão e seus impactos para a Saúde dos Trabalhadores, a partir do conceito ampliado de saúde e da transversalidade das demandas e das políticas públicas e sociais.

Neste contexto, constatou-se a importância e necessidade de um trabalho interdisciplinar, através da articulação dos saberes do Serviço Social e da Psicologia Social do Trabalho na intervenção junto às múltiplas dimensões apresentadas pelos casos atendidos na Secretaria de Saúde do Trabalhador.

Com o objetivo de lutar pela prevenção e promoção da atenção à saúde dos trabalhadores públicos por meio da melhoria contínua das condições e das relações de trabalho e da saúde, desenvolve-se um formato de educação permanente, qualificando o próprio trabalhador para a vigilância e o cuidado da sua saúde e da saúde de seus colegas nos diversos ambientes de trabalho em que estão inseridos. Atua-se também no apoio ao desenvolvimento e ao acompanhamento de atividades que abordam a qualidade de vida no trabalho, com ações de mobilização permanente voltadas à promoção, formação e proteção da saúde do trabalhador, através de estratégias conjuntas direcionadas à proteção à saúde dos trabalhadores públicos federais.

A SST/SINDISPREV-RS conta atualmente com uma equipe técnica composta de Assistente Social, Psicóloga Social do Trabalho e, ainda, alunos de graduação de ambas as áreas, que participam dessa construção através da experiência de estágio, em forma de trabalho interdisciplinar, fundamentado na interação entre as áreas de Ciências Humanas, Ciências Sociais e Saúde Coletiva, com ênfase na saúde do trabalhador. Além disso, as atividades desenvolvidas contam com a interface do trabalho no âmbito jurídico, com advogados que integram a assessoria especializada do sindicato, estabelecendo ações interdisciplinares entre as profissões, visando a integralidade no atendimento em saúde do trabalhador.

Algumas das principais ações desenvolvidas pela equipe técnica em conjunto com a direção do sindicato são: desenvolvimento da capacidade de observar a qualidade da relação entre a saúde e o trabalho no ambiente laboral, com a luta pelo desenvolvimento de ações de prevenção, promoção e vigilância da própria saúde e por condições de trabalho do trabalhador; 
acompanhamento e monitoramento da saúde dos trabalhadores públicos pela exigência da divulgação das informações oficiais relativas à situação da saúde do trabalhador, bem como a requisição, junto aos órgãos competentes, do mapa de afastamentos por doença e acidentes de trabalho e da situação atual de lotação nos postos de trabalho; capacitação dos trabalhadores para que estejam atentos ao processo de notificação dos agravos à saúde dos trabalhadores públicos, além de orientação e acompanhamento dos processos de afastamento e retorno ao trabalho por acidente ou adoecimento do trabalho. A equipe técnica, em apoio à direção do sindicato, reforça o compromisso da luta pela promoção da saúde dos trabalhadores públicos, favorecendo a criação e a manutenção de ambientes de trabalho seguros e saudáveis em suas múltiplas dimensões, consciente do fato de que se trata de uma luta coletiva que pode promover mudanças efetivas nas condições de trabalho atuais.

Nesse contexto, o papel da Psicologia Social do Trabalho e do Serviço Social abrange as mais diversas ações que vêm dos desdobramentos das condições e das relações laborais, que acaba por propiciar um processo de interação em que as especificidades do conhecimento se complementam para dar conta das demandas que se apresentam. É essa experiência que aborda a interface profissional da discussão que segue.

\section{A Interlocução da Psicologia Social do Trabalho e do Serviço Social e a Contribuição para o Trabalho na Secretaria de Saúde do Trabalhador}

A interdisciplinaridade nas ações proposta pela Secretaria de Saúde do Trabalhador permite a interface de duas profissões que possuem atuações diretamente ligadas ao trabalhador, que faz parte de todas as mudanças socio-históricas e das transformações sociais, políticas e econômicas na sociedade. O resultado dessas mudanças, que afetam o bem-estar psicossocial do trabalhador e da trabalhadora, é o que se torna o objeto de trabalho da Assistente Social e da Psicóloga Social do Trabalho. Desse modo, a necessidade de ambos profissionais atuarem de forma interdisciplinar nesse campo se deu a partir de visíveis demandas de trabalhadores que procuravam o sindicato não apenas com questões relacionadas à saúde e ao trabalho, mas também nas suas múltiplas dimensões da vida humana, exigindo dos profissionais um olhar mais ampliado sobre as demandas apresentadas.

A inserção da Psicóloga Social do Trabalho na equipe técnica da Secretaria de Saúde do Trabalhador se justificou pela necessidade de escuta e acompanhamento de questões vinculados às Clínicas do Trabalho perpassadas pela experiência da intervenção coletiva inspirada na Psicodinâmica do Trabalho proposta a partir de Dejours (1987), que compreende a visão de um 
sujeito que age e se constrói na interação com o trabalho, alternando prazer e sofrimento, observando as condições de mobilizações psíquicas que dão sentido ao trabalho. Outra inspiração para a intervenção é a Clínica da Atividade, proposta por Yves Clot (1995), que pressupõe que as relações entre a atividade de trabalho e a subjetividade estão permanentemente em análise, em um jogo de correlações e forças que ora se atraem ora se dispersam, ora se conflitam. Assim, a atividade do sujeito não está voltada apenas para seu objeto, que seria o trabalho, mas também para as atividades dos outros sobre este objeto, perfazendo assim, a clínica da atividade.

Assim, a construção da intervenção da Psicóloga nesse espaço específico de saúde do trabalhador consegue ampliar e compartilhar o vínculo clínico para o contexto sociolaboral dos trabalhadores em acompanhamento, que envolve uma gama de vivências e sofrimentos que se originam nas questões objetivas e subjetivas relacionadas ao trabalho (Bendassolli \& Sobol, 2010).

Como objeto dessa proposta de intervenção, destaca-se a relação entre o trabalho e o trabalhar, eixo central da constituição do sujeito, inspirada pela concepção proposta por Dejours (1987). O foco de análise parte da organização do trabalho, nas suas dimensões visíveis e invisíveis, prescritas, cognitivas, afetivas, intersubjetivas, política e ética. Conhecer a organização do trabalho é fundamental para acessar as vivências de prazer e de sofrimento, os processos de subjetivação, as patologias e as relações engendradas pelo processo de saúdeadoecimento. Identificar como os sujeitos constroem as estratégias de confrontamento com o real da organização do trabalho é crucial para a análise clínica, visto que é essa organização que promove e configura a construção dessas estratégias. Assim, a partir da relação dialética entre identificar e reconhecer ou não suas próprias demandas e a análise de como se produzem as subjetividades no contexto laboral tornam-se centrais para o desenvolvimento do trabalho, e, para isso, devem ser criadas estratégias em um contexto diferenciado do ambiente formal laboral. Estas estratégias permitem a relação entre a expressão e a fala do trabalhador em uma escuta clínica, fundamentada em um tripé envolvendo o conhecimento teórico-metodológico, a conduta clínica e a qualificação pessoal e profissional.

A escuta clínica que permite o privilégio da fala, não apenas focada na construção de um espaço de escuta, mas também no trabalho pedagógico de ensinar o falar e o escutar, busca colocar a palavra em ação, em uma oportunidade de pensar o trabalho em suas dimensões visíveis e invisíveis e de questionar a organização do trabalho e seus laços sociais, que são construídos a partir da relação dos sujeitos com o real. Assim, o trabalho baseado nas Clínicas do Trabalho é contemplado também em sua relação com o coletivo, promovendo no sujeito a 
oportunidade do exercício de se colocar no lugar do outro no momento que faz a sua fala fluir entre um grupo de trabalhadores que muitas vezes, não reflete comumente sobre as dimensões invisíveis do trabalho, os investimentos pessoais de cada um e a sua relação da subjetividade e do outro.

Outro fator importante ao trabalho da Psicóloga neste campo de atuação é a Psicologia Social, que compõe o olhar também voltado ao viés institucional e que observa além do trabalhador, o grupo, as relações interpessoais, a instituição e a organização. Estes elementos todos auxiliam a compreender não apenas a "queixa" ou o "sintoma", mas também os elementos pluridisciplinares a ela correlacionados, que se traduz nas mais diversas demandas que a secretaria recebe, cotidianamente.

Entre as ações desenvolvidas pela Psicologia, estão a atuação em processos judicializados vinculados à questões do âmbito da saúde mental e do trabalho, no papel de Assistente Técnico ou Psicólogo Perito, elaboração de laudos e pareceres psicológicos, apoio e intervenção em crise, assessoria especializada à direção do sindicato, visitas domiciliares e nos locais de trabalho, planejamento e execução de cursos, palestras e oficinas temáticas, elaboração de materiais informacionais, apoio psicológico nos casos necessários e guarda de documentos sigilosos pertinentes ao trabalho da Secretaria de Saúde do Trabalhador.

No que tange ao trabalho da Assistente Social e a compreensão de sua atuação dentro de uma entidade de classe, torna-se importante entender a categoria trabalho como elemento central, que perpassa toda atividade humana, se construindo historicamente na organização do contexto das relações sociais que se moldam com o trabalho e a partir dele. O Serviço Social se insere na Secretaria de Saúde do Trabalhador por compreender que a precarização do trabalho e o adoecimento são atualmente expressões importantes da questão social na busca da reafirmação de direitos sociais do trabalhador, construindo um espaço reflexivo das situações concretas do trabalho e de seus aspectos subjetivos, destacando a centralidade desse elemento na vida das pessoas. Assim, o fazer profissional na entidade coaduna-se diretamente com 0 próprio caráter da profissão, que é lutar a favor da classe trabalhadora, buscando contribuir para o fortalecimento do direito à saúde do trabalhador, propondo-se, portanto, a pensar o trabalho cotidiano com subjetividade, buscando (re)construir a (res)signific ação.

Integrando-se como profissional da saúde, conforme a Resoluçấo n. 383/99 do Conselho Federal de Serviço Social (CFESS), o Assistente Social contribui, por meio de seu trabalho, para a melhoria das condições de saúde buscando a efetivação do direito à saúde e a um ambiente de trabalho saudável, propiciando a promoção e a prevenção de situações laborais que causam o adoecimento. 
Em vista disso, no espaço de atuação é necessário um posicionamento político que pactue com o Projeto Ético Político da profissão, mostrando, assim, a importância da compreensão da relação entre saúde e trabalho e do processo saúde-doença dos trabalhadores. Para criar estratégias de trabalho e intervenção, há a necessidade de conhecer como e por que os trabalhadores adoecem e de que forma são organizadas e atendidas suas necessidades de saúde, com ênfase na compreensão do mundo do trabalho e nas novas formas de gestão, que são geradoras de doenças, com a finalidade de intervir politicamente para transformar a realidade.

As ações específicas do trabalho do Assistente Social em saúde do trabalhador se apresentam em amplos elementos como o acompanhamento em perícias de trabalhadores, como assistente técnico, de acordo com a Resolução CFESS n. 559/2009. Ainda, conforme a Lei 8.662/93 cabe também, de forma privativa, a coordenação, elaboração, execução de pesquisas, planos, informações e pareceres técnicos na área de serviço social, no que se refere ao campo, bem como assessoria e consultoria. Assim, o sindicato amplia sua estratégia de luta para além de ações e atendimento aos trabahhadores públicos e proporciona espaço para o processo de formação profissional de acadêmicos, requerendo, para tanto, a atribuição privativa de supervisão de estágio curricular em serviço social, fomentando a construção de diversos estudos com a temática na qual está inserido.

Além disso, o segmento de aposentados que frequentam o sindicato também se apresenta com as mais diversas expressões da questão social, como a falta de informações, a violência, o endividamento, as fragilidades de vínculos familiares ou a ausência deles e etc. $\mathrm{O}$ fazer profissional abrange acolhimento, visita domiciliar e também articulação com a rede de políticas públicas e sociais para denúncia e acesso aos direitos dessa população.

Desse modo, no sindicato, esse tipo de intervenção se desmembra no cotidiano de trabalho e compreende as mais diversas atribuições, algumas em caráter compartilhado entre as duas áreas de conhecimento que atuam no espaço da Secretaria de Saúde do Trabalhador. Apesar da peculiaridade de ambas as profissões, a questão da defesa e a contribuição para o acesso aos direitos dos trabalhadores públicos federais perpassam as duas profissões que contrapondo à insuficiência das informações sobre seus próprios direitos, prestam acolhimento e orientação aos trabalhadores, a partir de escuta acolhedora e qualificada, orientando nos períodos de pré e pós aposentadoria, nas situações de remoções por motivo de saúde, e/ou orientações nas aposentadorias por invalidez, registro e acompanhamento dos acidentes e doenças do trabalho, apoio durante os processos administrativos disciplinares (PAD), bem 
como realizando ações que envolvem o tema da saúde dos trabalhadores, entres outras questões que estão alicerçadas na lei 8.112/90, o estatuto dos trabalhadores federais.

A forma, ou formato que acabamos por desenvolver durante o atendimento na secretaria de saúde do trabalhador do sindicato é baseada nos preceitos da Clínica Ampliada e Compartilhada em Saúde, que fornece suporte e propicia um momento de descoberta da singularidade de cada um, cuja proposta "busca se constituir numa ferramenta de articulação e inclusão dos diferentes enfoques e disciplinas" (Ministério da Saúde, 2009, p. 10). Para a Clínica Ampliada, "em um dado momento e situação singular, pode existir uma predominância, uma escolha, ou a emergência de um enfoque ou de um tema, sem que isso signifique a negação de outros enfoques e possibilidades de ação" (Ministério da Saúde, 2009, p. 10).

A proposta compreende que toda profissão faz um recorte, um destaque de sintomas e informações específicas e direcionadas, cada uma de acordo com as diretrizes seu núcleo profissional. Ampliar a clínica, nesse sentido, significa justamente ajustar os recortes teóricos de cada profissão às necessidades dos trabalhadores, o que propicia, no espaço da Secretaria, o trabalho interdisciplinar da Psicologia e do Serviço Social. Essa interação permanente busca evitar um formato único que privilegie excessivamente alguma matriz de conhecimento disciplinar, em uma forma complementar, em que cada teoria faz um recorte parcialmente arbitrário da realidade (por exemplo, na mesma situação clínica e/ou social, podem-se perceber vários aspectos: patologias orgânicas, forças sociais, produção de subjetividade, aspectos socioculturais e assim por diante), e no qual cada recorte poderá ser mais ou menos relevante a cada momento do acompanhamento. O apoio, nessa metodologia, busca construir sínteses singulares tensionando os limites de cada matriz disciplinar e colocando em primeiro plano a situação real do trabalho em saúde, vivida a cada instante por sujeitos reais. Esse eixo da Clínica Ampliada traduz-se ao mesmo tempo em "um modo de fazer a clínica diferente e na ampliação do objeto de trabalho, com a necessária inclusão de novos instrumentos" (Ministério da Saúde, 2009, p. 26).

Ao observarem-se os casos recebidos pelo sindicato, imediatamente puderam ser identificados os complexos sintomáticos mais comuns e frequentes, tais como: reações de ansiedade agudizadas, reações depressivas, reações fóbicas e/ou estados de pânico, quadros dissociativos, quadros de esgotamento e/ou burnout instalados, reações psicóticas agudas, reações neurastênicas multidimensionadas, uso abusivo de álcool e medicamentos psiquiátricos para alívio de sintomas referentes a situações estressoras, distúrbios de sono, ideação suicida, transtornos psicossomáticos e culminação em tentativa de suicídio, nos quadros mais graves. Nesse contexto, o processo de investigação diagnóstica realiza os mesmos protocolos gerais 
que são utilizados nos serviços de saúde, com investigação de história pregressa, história da vida laboral, histórico do transtorno mental, caracterização dos sintomas fundamentais e sua associação a aspectos relacionados ao trabalho.

Portanto, a atuação interdisciplinar aqui proposta explicita a necessidade de integralidade da atenção na saúde do trabalhador, atenta não somente aos aspectos clínicos, mas também às questões de condições sociais e de trabalho pertinentes ao exercício da vigilância permanente em saúde do trabalhador, conforme preconizado tanto pela Política Nacional de Saúde do Trabalhador e da Trabalhadora (PNST, 2012) quanto pelas diretrizes definidas pelo Sistema Único de Saúde (SUS, 1998).

\section{Encontros Regionais de Saúde do Trabalhador como Fonte de Estratégias Coletivas}

Como forma de aproximação da realidade da categoria representada pelo sindicato que possui atuação em âmbito estadual, a Secretaria de Saúde do Trabalhador propõe, junto à direção da entidade, a realização de encontros regionais periódicos no interior do estado do Rio Grande do Sul a fim de aproximar e sensibilizar a categoria para a discussão de suas condições de trabalho e capturar demandas de trabalho e portanto, direciona a luta sindical.

Os encontros regionais com os trabalhadores têm como objetivo propiciar a discussão e a reflexão sobre a saúde do trabalhador e sobre a realidade dos locais de trabalho dos trabalhadores federais. Além disso, espera-se, durante os eventos, realizar diagnóstico situacional relativo às condições de trabalho e à saúde do trabalhador, proporcionando reflexão, debate e fomento de propostas de intervenção para prevenção e promoção de ações de proteção à saúde dos trabalhadores nas regionais de atuação no estado do Rio Grande do Sul.

O tema central dos encontros que foram realizados no período de 2014 a 2018 , em um primeiro momento, foi o adoecimento relacionado ao trabalho, com foco no impacto do processo de precarização das condições de trabalho na saúde mental dos trabalhadores. $\mathrm{O}$ delineamento desse trabalho se deu em virtude das estatísticas oficiais da Previdência Social sobre acidentes e doenças do trabalho no Brasil, que se referem aos trabalhadores do regime geral que apontaram os transtornos mentais e do comportamento como atual desafio para adoecimento no trabalho. Observamos a invisibilidade destas informações no serviço público federal, ocasionados pela falta de transparência e acesso aos dados de adoecimentos dos trabalhadores públicos, não publicizados pelas vias oficiais. Além disso, a realidade cotidiana trazida pelos trabalhadores à Secretaria de Saúde do Trabalhador do sindicato vai ao encontro 
dos estudos mencionados e está em consonância com as estatísticas gerais dos trabalhadores em regime CLT, divulgada anualmente pelo anuário estatístico do INSS.

Os encontros foram projetados com a integração de atividades que contemplaram algumas partes expositivas e dialogadas, intercalando-se palestras e discussões coletivas, que culminaram em uma atividade conjugada e em uma oficina em forma de trabalho com pequenos grupos, agregados por região, dando o caráter de mapeamento de território e condições de trabalho de forma local. Essa estratégia proporcionou a interação entre a reflexão e o debate coletivo dentro de uma mesma gerência, ampliando a visão sobre a necessidade constante das trocas coletivas, além de instrumentalizar os trabalhadores para a realização da vigilância sobre seu próprio ambiente de trabalho e de sua saúde, viabilizando, consequentemente, o fortalecimento do coletivo regional.

$\mathrm{Na}$ abertura de cada encontro houve uma apresentação da secretaria, assim como da equipe técnica e de demais diretores e trabalhadores do SINDISPREV-RS. A seguir, foram desenvolvidas palestras com temas referentes à saúde dos trabalhadores, tais como: "Trabalho Precário e o Impacto na nossa Saúde", "Assédio Moral no Trabalho" e, ainda, "Saúde do Trabalhador" e "Questões Jurídicas e Saúde do Trabalhador", que são assuntos diretamente envolvidos no processo de adoecimento. Observou-se que durante as explanações houve bastante mobilização entre os participantes, gerando algumas discussões paralelas às apresentações, que foram trabalhadas no espaço coletivo posteriormente, o que proporcionou espaço para a fala dos trabalhadores.

Em uma segunda parte do trabalho, foi desenvolvida uma oficina em forma de pequenos grupos de trabalho, que objetivou a reflexão coletiva dos temas apresentados. Nela, como produto, cada grupo produziu a sua própria análise sobre as condições e os ambientes de trabalho aos quais estão submetidos, exercitando-se assim, a vigilância em saúde do trabalhador.

O produto desses encontros resultou, posteriormente, em um diagnóstico situacional ampliado a todas as regiões do estado, produto final do ciclo de encontros regionais. Esses encontros foram realizados de forma sistemática em nove delegacias regionais do sindicato e contaram com a participação de mais de 400 trabalhadores de vários órgãos partícipes.

A partir do trabalho realizado com os grupos de trabalhadores foi possível perceber alguns marcadores considerados como negativos, por exemplo: pressão permanente por produção, controle excessivo por parte das chefias, identificação dos riscos do processo de trabalho informatizado, intensificação do trabalho pela sobrecarga, diminuição crescente da força de trabalho por aposentadorias e falta de reposição, extinção de serviços, terceirização, 
insegurança quanto às questões de afastamento por saúde, pois alguns órgãos dificultam o reconhecimento das doenças relacionadas ao trabalho e, por fim, violência econômica pela remuneração (sistema de gratificações) vinculada à produtividade. Por outro lado, há outros marcadores identificados como positivos, como: desejo e possibilidade de controle sobre o processo de trabalho por parte dos trabalhadores, opção pelo teletrabalho como alívio da carga emocional que o atendimento direto ao público gera, diminuição de atritos nas relações interpessoais pela comunicação (a partir de agora somente via sistema, ou seja, sem a necessidade de ser pessoal, o que poderá diminuir a violência e o assédio moral no trabalho), e abertura de canal direto com o sindicato via Secretaria de Saúde do Trabalhador.

Foi a partir desses marcadores, apresentados por meio das experiências e dos sentimentos externalizados a partir das reflexões críticas nos grupos pelos próprios trabalhadores, que a Secretaria e a equipe técnica contribuíram com o SINDISPREV-RS na elaboração de seus instrumentos de luta em defesa da categoria por ele representada.

Como eixos de ações a serem planejadas e executadas pelo sindicato são apontados: o seguimento na luta pelos direitos dos trabalhadores da esfera pública, a melhoria das condições de trabalho, o enfrentamento e o combate do assédio moral e o apoio no planejamento do processo de aposentadoria.

\section{O Trabalho na Secretaria de Saúde do Trabalhador: perfil dos casos atendidos pela equipe}

Com o objetivo de apoiar de forma integral a gestão do sindicato no que diz respeito ao planejamento e às execuções de ações e projetos, destinada a atender às diversas demandas da categoria, a Secretaria de Saúde do Trabalhador tornou-se um canal aberto permanente de diálogo entre o sindicato e a categoria. Os atendimentos individuais e/ou coletivos não se configuram apenas no âmbito da saúde do trabalhador, ou seja, as demais demandas com ênfase no apoio psicossocial apresentadas à instituição são igualmente acolhidas pela equipe e posteriormente encaminhadas aos trâmites que se façam necessários, sendo isso definido caso a caso.

No período entre março de 2014 e dezembro de 2017 foram identificados 185 casos individuais e 14 casos coletivos. Desses casos, $83,1 \%$ referiram-se ao atendimento a mulheres e $4 \%$ ao atendimento a homens, sendo que $12,9 \%$ foram casos coletivos. A faixa etária predominante era entre 50 e 70 anos, demonstrando a importância das ações voltadas à preparação da aposentadoria, pois sabe-se que a maioria dos casos está em abono de 
permanência no Serviço Público Federal. Com relação às demandas recebidas, registramos em $55,30 \%$ casos referentes ao assédio moral no trabalho, em $44,24 \%$ ocorrências relativas a conflitos no ambiente de trabalho, 38,21\% com situações relativas ao direito à saúde judicializadas, 27,20\% em casos com necessidade de suporte e acompanhamento psicossocial e 9,5\% de demandas de acompanhados por estarem respondendo processos administrativos (PAD).

Com relação ao adoecimento, observou-se que, dos casos individuais recebidos, $44 \%$ se apresentaram sem diagnóstico de saúde, porém, com o passar do tempo, foram encaminhados a profissionais de saúde por se tratar de casos absolutamente vulneráveis ao adoecimento. Observa-se também, conforme expressa a literatura da área, uma maior parcela de mulheres que já buscaram ajuda para problemas de saúde decorrentes do trabalho (50\%) no comparativo com os homens, considerando-se que em torno de 15\% dos que buscaram a Secretaria de Saúde do Trabalhador aceitaram o encaminhamento para tratamento de saúde. Nos demais casos de homens atendidos, ainda que de modo resistente, em face ao quadro de adoecimento já bastante agravado ao buscarem o apoio do sindicato, a doença já estava instalada, o que dificulta muitas vezes aspectos referentes ao tratamento e à ajuda relativos a determinados quadros de saúde mental, tais como: depressão, fobias e quadros ansiogênicos.

Referentemente às demandas recebidas, também foi possível observar que $72 \%$ das situações que se apresentaram aos trabalhadores nos ambientes de trabalho foram oriundas de desacordo com o patrão e/ou colegas de trabalho (CID Z56.4) e 20\% eram relativas ao ritmo de trabalho penoso (CID Z56.3). Cabe observar que a documentação médica de muitos desses casos apresentava como diagnósticos depressivos (CID F32) e também massivamente como Transtorno de Ansiedade (CID F41). Todavia, observou-se que a maioria dos casos identificados inicialmente como depressivos e/ou ansiosos, demonstraram, após o aprofundamento da investigação diagnóstica pela equipe da SST, tratar-se de Transtorno de Estresse Pós-Traumático (TEPT), provocado por algum conflito no trabalho ou proveniente do clima hostil presente nos próprios ambientes laborais. Estes casos, em sua maioria, se apresentaram inicialmente sem o nexo com o trabalho reconhecido em laudos oficiais, o que resulta na invisibilidade do adoecimento e dos agravos à saúde dos trabalhadores federais afastados do trabalho.

Esse fato deve-se provavelmente à falta de conhecimento e reconhecimento por parte dos profissionais da saúde, ou seja, dos profissionais assistentes que atenderam os trabalhadores, e à dificuldade em avaliar e definir o diagnóstico de saúde, com prejuízos à saúde dos trabalhadores decorrentes do trabalho nos sintomas demonstrados pelos casos atendidos 
pelo sindicato. Os transtornos mentais e do comportamento, igualmente observados no anuário estatístico da Previdência Social (Ministério da Fazenda, 2018), também expressam essa dificuldade. Por um lado, reconhecem-se as patologias relativas à saúde mental e suas gravidades decorrentes, mas pouco se reconhece o nexo das mesmas com o trabalho, de modo que essas patologias são reconhecidas muitas vezes apenas para fins de benefício, e não de dano ou dolo, o que contribui para sua invisibilidade.

\section{CONSIDERAÇÕES FINAIS}

As transformações nos modos de produção que atendem aos interesses do capital produzem efeitos nas relações sociais, políticas e culturais no mundo do trabalho. As contradições resultantes dessas transformações decorrentes da reestruturação produtiva também são observadas no serviço público, a partir da reforma do Estado iniciada na década de 1990, e, assim, refletem em expressões da relação entre o capital e o trabalho se constituindo como um processo histórico permanente de mutação e transformação. O trabalho precarizado, reflexo dessa relação, é visto dentro do serviço público com as alterações constantes na gestão do trabalho, marcada agora pela informatização crescente e pelo intenso uso das Tecnologias da Informação e Comunicação (TICs) (Antunes, 2018).

A classe trabalhadora se encontra fragmentada, alienada à sua dimensão coletiva, o que se torna um obstáculo na organização dessa classe para reivindicar os direitos conquistados na Constituição Federal de 1988, através de lutas sindicais e de outras organizações trabalhis tas. Tal fragmentação, além de obstáculo, se transforma em um mecanismo de controle do capital, que se utiliza de fatores como a competitividade e a instabilidade no emprego como formas de perpetuação dessa partição.

Nesse cenário de capitalismo globalizado, é importante atentar para os desafios enfrentados pela classe trabalhadora em faceda possibilidade de avanço do processo de mercantilização dos direitos e das necessidades sociais, que resulta na desregulação das políticas sociais e do Estado, que se encontra cada vez mais capturado pelas demandas do capital.

A reestruturação produtiva no serviço público federal na área da Seguridade Social promoveu a supressão de órgãos e dispersão dos trabalhadores e respectivos serviços nos 26 estados da União. Esse processo foi acompanhado pela introdução de novas formas de gestão dos órgãos públicos, que incluíram novos mecanismos de controle dos processos de trabalho, diminuindo a autonomia e a criatividade do trabalhador. A mudança na relação homem-trabalho 
ficou evidenciada no serviço público e está refletida diretamente na precarização das condições de trabalho, exemplificada pela falta de estruturas físicas adequadas, pela ampliação dos afastamentos por adoecimentos ligados à saúde mental, pelo aumento nos casos de assédio moral e pela perda da identidade enquanto categoria profissional, o que resulta no esvaziame nto do trabalhador e do próprio trabalho.

Assim, o trabalho desenvolvido pela Secretaria de Saúde do Trabalhador, atenta aos impactos dessas mudanças nas formas de gestão, encontra pauta permanente junto aos trabalhadores públicos atendidos. Em uma época de predomínio do individualismo possessivo e de pragmatismo do mercado, a adoção de modelos de gestão privada na gestão das políticas públicas pode transformar-se em estratégia de destruição dos valores do bem comum no campo público, consequentemente levando ao aumento das desigualdades e das exclusões sociais. Os valores considerados pelas políticas públicas visam atender necessidades, preocupações e propósitos coletivos da sociedade em seu caráter universal. Nesse sentido, a gestão dos serviços públicos é também uma gestão de processos políticos, relacionais, processuais, afetivos, éticos e sociais, implicando o reconhecimento de que o próprio contexto dos serviços é atravessado por conflitos, desigualdades, diversas visões do mundo e confronto de diferentes racionalidades, não sendo, por isso, a gestão uma questão de simples competência técnica ou instrumental, finda em si mesma.

O resultado dessa experiência, como forma de contribuição para a identificação e o acompanhamento desses casos de trabalhadores públicos expostos aos agravos à própria saúde, requer uma atenção especial de seus gestores. Como desafio, serão necessárias, ainda, a qualificação e a sensibilização do olhar das equipes envolvidas nas perícias dos trabalhadores nos seguintes aspectos: mapear e reconhecer os agravos à saúde mental relacionados ao trabalho; fornecer suporte e segurança, através do acompanhamento sistemáticos dos casos, contemplando a suspeição, a investigação, o diagnóstico e o nexo com o ambiente de trabalho, para que o trabalhador adoecido possa ser acolhido e ter suas necessidades atendidas, bem como receber o correto encaminhamento da situação; introduzir a cultura da notificação de agravos à saúde do trabalhador, tanto na emissão da Comunicação de Acidentes de Trabalho do Serviço Público (CAT-SP) quanto no Registro dos Agravos à Saúde do Trabalhador junto ao Sistema de Informação de Agravos de Notificação (SINAN), que pode ser efetuada em qualquer serviço de saúde do SUS e compreende, inclusive, as situações de violências vividas durante o expediente de trabalho. Importante destacar que o reconhecimento dos acidentes e doenças relacionados ao trabalho no serviço público ainda é algo desconhecido por parte dos trabalhadores públicos, o que reforça sua invisibilidade. 
Considerando-se todos os elementos que este relato de experiência traz através do trabalho interdisciplinar, impulsionado pelo Serviço Social e pela Psicologia Social do Trabalho, aqui compreendidos como áreas complementares e fundamentais para a saúde do trabalhador, busca-se uma forma de atuação que denota atenção especial às mudanças em curso no serviço público do país. Portanto, o SINDISPREV-RS se propõe como um espaço de acolhida e atenção psicossocial para o trabalhador público, objetivando, além do atendimento direto, o diálogo permanente com os gestores e trabalhadores. O trabalho é desenvolvido levando em conta a dimensão política das ações junto à sua categoria, fomentando o fortalecimento do movimento e da saúde do trabalhador na entidade.

\section{Referências}

Alves, G. Nassif, Maria Inês, Rosário, Miguel do. Filho, Wilson Ramos (coord.); Gonçalves, Mírian (org.). Enciclopédia do golpe - Vol. 1. Introdução, Alves, 2017 - Bauru: Canal 6, 2017. 251 p. (Projeto Editorial Praxis).

Alves, Giovanni. (2007). Dimensões da reestruturação produtiva: Ensaios de sociologia do trabalho. São Paulo: Práxis.

Antunes, Ricardo., \& Alves, Giovanni. (2004). As mutações no mundo do trabalho na era da mundialização do capital. Educação e Sociedade, 25(87),335-351. Acessado em: 16 de agosto de 2015, de: 〈http://www.scielo.br/pdf/es/v25n87/21460.pdf〉.

Antunes, R. (2018). O privilégio da servidão: O novo proletariado de serviços na era digital. São Paulo: Boitempo.

Bendassolli, P., \&Sobol, L. (2010). Introdução às clínicas do trabalho: Aportes teóricos, pressupostos e aplicações. In P. F. Bendassolli, \&L. A. P. Sobol (Org.), Clínicas do trabalho: Novas perspectivas para compreensão do trabalho na atualidade (pp. 71-83). São Paulo: Atlas.

Biavaschi, M. Verbete Reformas Estruturantes. In. Enciclopédia do golpe. Alves e Cols. - Vol. 1. - Bauru: Canal 6, 2017. 251 p. (Projeto Editorial Praxis).

CFESS. Conselho Federal de Serviço Social - Lei de Regulamentação da Profissão/ Lei no 8.662, junho de 1993.

Clot, Y. (1995). Le travailsansL'homme? Pour une psychologie de milieux de travail et de vie. Paris: La Découverte.

Dejours, C. (1987). A loucura do trabalho: Estudo de psicopatologia d otrabalho. São Paulo: Cortez. 
Franco, Tania., Druck, Graa., \& Seligmann- Silva, Edith. (2010). As novas relações de trabalho, o desgaste mental do trabalhador e os transtornos mentais no trabalho precarizado. Revista Brasileira de Saúde Ocupacional, 35(122),229-248. Acessado em: 16 de agosto de 2015,

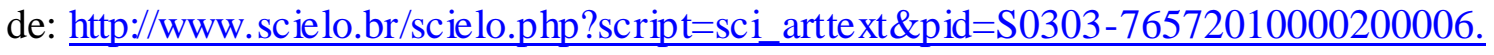

Lei n. 13.467, de 13 de julho de 2017. Altera a Consolidação das Leis do Trabalho (CLT), aprovada pelo Decreto-Lei n. 5.452, de 1 de maio de 1943, e as Leis n. 6.019, de 3 de janeiro de 1974, 8.036, de 11 de maio de 1990, e 8.212, de 24 de julho de 1991, a fim de adequar a legislação às novas relações de trabalho. Recuperado de: http://www.planalto.gov.br/ccivil_03/_ato2015-2018/2017/lei/113467.htm.

Machado, Fabiane Konowaluk Santos, Giongo, Carmem Regina, \& Mendes, Jussara Maria Rosa. (2016). Terceirização e Precarização do Trabalho: uma questão de sofrimento social. Revista Psicologia Política,16(36), 227-240. Recuperado em 12 de dezembro de 2018, Recuperado de: $\leq$ http://pepsic.bvsalud.org/scielo.php?script=sci_arttext\&pid=S1519549X2016000200007\&lng=pt\&tlng=pt>.

Ministério da Fazenda (2018). Dados abertos: Previdência Social e INSS. Recuperado de http://www.previdencia.gov.br/dados-abertos/dados-abertos-previdencia-social/.

Ministério da Saúde (2009). Clínica ampliada e compartilhada. Brasîlia: Ministério da Saúde. Recuperado http://bvsms.saude.gov.br/bvs/publicacoes/clinica_ampliada_compartilhada.pdf.

Resolução n. 383, de 29 de março de 1999. Dispõe sobre a caracterização do Assistente Social como profissional da Saúde. Recuperado de: http://www.cfess.org.br/arquivos/resolucao_383_99.pdf.

Resolução n. 559, de 16 de setembro de 2009.Dispõe sobre a atuação do Assistente Social, inclusive na qualidade de perito judicial ou assistente técnico, quando convocado a prestar depoimento como testemunha, pela autoridade competente. Recuperado de: http://www.cfess.org.br/arquivos/Resolucao_CFESS_559-2009.pdf.

Sindicato dos Trabalhadores Federais da Saúde, Trabalho e Previdência no Rio Grande do Sul (2013). Estatuto do Sindicato dos Trabalhadores Federais da Saúde, Trabalho e Previdência no Estado do Rio Grande do Sul.Porto Alegre: Gestão 2013/2017 do Sindicato dos Trabalhadores Federais da Saúde, Trabalho e Previdência no Rio Grande do Sul.

Skinner, M. Verbete Projeto Neoliberal. In. Enciclopédia do golpe Bauru: Canal 6, 2017.251 p. (Projeto Editorial Praxis).

Teixeira, Gustavo Ramos et al. (coords.). O golpe de 2016 e a reforma da previdência: narrativas de resistência /- Bauru: Canal 6, 2017. 478 p.; $23 \mathrm{~cm}$. (Projeto Editorial Praxis). 